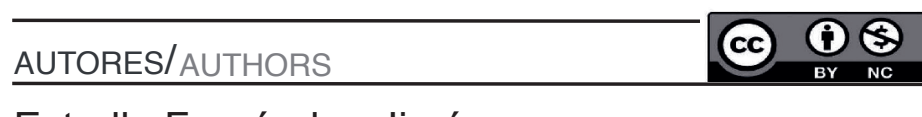

\title{
La glocalización del Carnaval de Cádiz en sus agrupaciones a través de la comunicación no verbal. Lo que dicen sin hablar ni cantar
}

\author{
The glocalization of the Cádiz carnival in its groups through non-verbal \\ communication. What they say without speaking or singing
}

\section{RESUMEN}

Este artículo muestra la importancia que la comunicación no verbal tiene en una de las manifestaciones culturales y artísticas más representativas de Andalucía: el Carnaval de Cádiz. A través de testimonios de protagonistas e investigación teórica, exponemos cómo las agrupaciones de carnaval muestran representaciones sociales gracias a sus letras y su expresividad. Se trata de un acontecimiento local que poco a poco se va convirtiendo en global apareciendo la glocalización (con «c») de esta manifestación cultural. La letra y la música son fundamentales en esta fiesta, pero por primera vez, estudiamos de manera precisa la importancia que la comunicación no verbal tiene en ella. Esta manera de comunicar refuerza el lado artístico y añade potencial comunicativo a este carnaval. Lo no verbal también fomenta la industria artesanal de la ciudad de Cádiz: creación de los disfraces, diseño de puesta en escena, forillo y atrezo. En este artículo manifestamos cómo esa expresividad transmitida a través de la comunicación no verbal dota de mayor fuerza al mensaje cantado por las agrupaciones de carnaval. Con este trabajo incorporamos, además, otra línea de investigación al Carnaval de Cádiz, tema en auge académico con una Cátedra desde 2018 en la Universidad de Cádiz.

PALABRAS CLAVE:

carnaval, Cádiz, Comunicación no verbal, COAC

\section{ABSTRACT}

This article shows the importance that non-verbal communication has in one of the most representative artistic and cultural manifestations of Andalusia: the Cádiz carnival. Through testimonies of protagonists and theoretical research, we expose how carnival groups show social representations thanks to their lyrics and expressiveness. It is a local event that gradually becomes global. This is how the glocalization (with "C») of this cultural manifestation appears. The lyrics and music are fundamental in this tradition, but for the first time, we study precisely the importance that non-verbal communication has in it. This way of communicating reinforces its artistic side and adds communicative potencial to this carnival. Non-verbal features also fosters the artisanal industry of the city of Cáfiz: creation of costumes, staging design, «forillo» and props. In this article we show how this expressiveness transmitted through non-verbal communication gives 
Estrella Fernández-Jiménez "La glocalización del Carnaval de Cádiz en sus agrupaciones através de

la comunicación no verbal. Lo que dicen sin hablar ni cantar". Comunicación y Hombre. 2022, $n^{\circ} 18$, pp 46 - 61. DOl: https://doi.org/ 10.32466/eufv-cyh.2022.18.699.46-61

greather strength to the message sung by carnival groups. With this work, we also incorporate another line of research into the Cádiz carnival, a topic that has been on the rise with a University chair since 2018 at the University of Cádiz.

\section{KEYWORDS:}

Carnival, Cádiz, non-verbal communication, COAC

\section{Introducción}

El Carnaval de Cádiz está ganando relevancia académica desde hace unos años. En 2018 se creó la Cátedra de Carnaval en la Universidad de Cádiz. Con este trabajo nos acercamos al carnaval para seguir mostrando un mundo de creatividad, expresividad y representación muy amplio. El Carnaval de Cádiz es creatividad, coplas, crítica y actualidad. Siempre es representación de la sociedad y de cualquier aspecto de la vida y comunicación, comunicación en todas sus facetas, incluyendo la comunicación no verbal, que es el tema del que trata este artículo.

Abordamos el tema contando con el testimonio de algunos de los protagonistas y autores de este fenómeno cultural. Unimos así los conocimientos de la participación en la fiesta con el desarrollo teórico y el ámbito académico. Intentamos equilibrar teoría y práctica con un estudio lo más completo posible que nos permita profundizar en el campo audiovisual, artístico e inclusive antropológico.

Recientes estudios han resaltado la importancia de las coplas y de las composiciones de las letras y músicas de este carnaval, afirmando incluso que forman un género literario independiente (Páramo Fernández-Llamazares, 2017). Ciertamente, las coplas son la base del carnaval gaditano. Además, otras publicaciones (Fernández Jiménez, 2015) han destacado que habitualmente el humor y lo socialmente entendido como grosero o escatológico eclipsa su principal característica que es la creatividad. Para que se produzca el humorismo, la sorpresa o el efecto irrisorio deseado ha de existir creatividad, y las agrupaciones carnavalescas usan además de la palabra cantada otras herramientas audiovisuales para realizar la representación como es la comunicación no verbal.

[EI COAC, Concurso Oficial de Agrupaciones Carnavalescas] se ha convertido en un espectáculo audiovisual lo cual, muchas veces ha resultado una crítica a las agrupaciones más modernas porque parece que aquí llevar un forillo negro da un plus de calidad y no es así necesariamente. Simplemente hay que adaptarse a los tiempos. Antes solo se escuchaba por la radio y se veía una foto al día siguiente en los periódicos, pero hoy día se retransmite en directo por televisión y está colgado en internet... Por lo tanto [...], se ha convertido en un espectáculo audiovisual y lo que se ve en el Teatro son auténticas obras de arte por parte de los artesanos que te encuadran en un marco que hace que el espectador vea más creíble todavía la obra que has preparado. (Manuel Morera, 2018, declaraciones en el programa de radio Mira que te diga).

El Carnaval de Cádiz enriquece cada vez más a las artes escénicas y a la industria cultural, que no es otra cosa que el consumo de cultura (Sacaluga y Pérez, 2017). El carnaval y su peculiar modo de comunicación están muy vinculados con el humor y el humor es polifacético y hace pensar. Para hacer reír entran en juego multitud de elementos: es fundamental el contenido de lo que se está expresando, pero igual de importante es cómo se está expresando. Un ejemplo esclarecedor de la importancia de 
Estrella Fernández-Jiménez "La glocalización del Carnaval de Cádiz en sus agrupaciones através de la comunicación no verbal. Lo que dicen sin hablar ni cantar". Comunicación y Hombre. 2022, $n^{\circ} 18$, pp 46 - 61. DOl: https://doi.org/ 10.32466/eufv-cyh.2022.18.699.46-61

lo no verbal en la cultura y en el humor ha sido el caso del humorista malagueño "Chiquito de la Calzada» cuya manera de expresar y representar la acción de los chistes lo convirtieron en emblema del humor en España.

El fenómeno de la glocalización se aprecia en las tradiciones de Andalucía. Hacer que una fiesta con arraigo local, en la que por ejemplo, se expanda una letra dedicada a un barrio de Cádiz pueda llegar a todas partes del mundo gracias al potencial comunicativo de las coplas y ayudadas por los medios de comunicación, es algo que en las últimas tres décadas viene sucediendo. Al igual que se expanden sus letras, en una sociedad en la que la imagen está en cualquier parte gracias a la red y los smartphones, la comunicación no verbal se expande igualmente y esta merece un estudio aparte, como es el presente trabajo.

Las agrupaciones del Carnaval de Cádiz están hechas para oírse y también para verse. Usar gestos para resolver alguna situación del repertorio no es algo nuevo ni influido en su totalidad por la televisión, idea asentada entre muchos aficionados y autores -que en ciertos momentos la influencia que ejerce la televisión en la interpretación es real-, pero ya en 1884 en la agrupación "Los Cocineros» hubo un caso de censura de una copla en la cual cantaban «El chocolate se hace así, así, así» (Ramos Santana, 2002). Es decir, lo no verbal siempre ha estado presente en las agrupaciones, pudiendo ser censurada una letra solo por los gestos que realizaba y estando la gracia en lo no verbal. Muchos seguidores del Carnaval de Cádiz, entiéndase del Concurso Oficial de Agrupaciones, siguen defendiendo el medio radiofónico como principal medio de comunicación, ya que les gusta imaginar el tipo y así prestar mayor atención al contenido de la letra sin «distracciones». Una opinión compartida por muchos, pero lo cierto es que cuando "va telón/van cortinas», se ve a la agrupación y el tipo aparece en escena es cuando cobra sentido el nombre a modo de acertijo que últimamente usan las agrupaciones e, inmediatamente después, queda fijado con el contenido de las letras. «La copla se canta con la chirigota parada, acompañándola con unos movimientos de brazos y de gestos que son la sal y la pimienta con que se adoban las letras. En muchas ocasiones el gesto dice más que la letra» (Solís, 1966, pp. 8-9). Esa «sal» y esa «pimienta» es lo que destacamos en este estudio como ingredientes fundamentales de estas creaciones.

\section{2. ¿Qué vemos?}

Al levantarse las cortinas del Falla nos encontramos con la puesta en escena y casi siempre con los tipos, que son la encarnación de una idea o personaje (Barceló Calatayud, 2016), son representaciones sociales. La plasmación del tipo en el disfraz es el elemento visual más importante de las agrupaciones. No solo es el atuendo, va más allá porque implica contenido. 
El disfraz constituye uno de los elementos más característicos del Carnaval y también del teatro. En efecto, el primer requisito para que pueda darse éste consiste en la actuación de un actor, es decir, una persona, que momentáneamente abandona su personalidad para asumir otra, para representar a alguien distinto de quien realmente es, ante un público. [...] Máscaras, pelucas, vestuario, impostación de la voz, actitudes y gestos, ideolecto o forma de hablar características del personaje en razón de su extracción social y geográfica, idiosincrasia, etc. (Cuesta Torre, 2010, pp. 43-44).

No solo se trata de disfrazarse, hay que interpretar. En el programa de radio Mira que te diga (2018), a la pregunta de si se sienten actores, teniendo en cuenta que no han estudiado interpretación, los autores «El Canijo de Carmona», Manuel Morera y «EI Selu» contestan lo siguiente:

Yo considero que sí, que una fruta se tiene que mover de una manera, que un lápiz se tiene que mover de otra, o que un bolígrafo de cuatro colores tiene que ser gordito. («El Canijo de Carmona»).

Yo creo que estamos actuando, estamos representando un papel con sus virtudes y con sus defectos. Nos sentimos actores en la medida en que en el momento en el que nos enfundamos el tipo pasamos a ser otra persona, [...] cuando estás interpretando estás haciendo un recurso actoral. No somos actores de estudio, pero tampoco creo que haga falta. (Manuel Morera).

Sí, nosotros somos pseudo todo, pseudo escritores, pseudo músicos, pseudo actores. Somos un proyecto de todo eso. Luego, te vienen actores como me han venido muchos, amigos míos y valoran muchísimo todo esto porque ellos ven cosas que a lo mejor la gente del Carnaval pues solamente se quedan con que es carnaval, pero ellos a lo mejor ven más allá [...], que con gestos de la cara y movimientos del cuerpo, como el año de «Los Enteraos», esa superioridad, el hecho de que el personaje te hablara desde arriba. Eso se estudia y nosotros pues, lo hemos ido poniendo en práctica de manera más artesanal quizá. («El Selu»).

Cada autor de Carnaval crea su propio poncif, o modo particular de escribir, su estilo. Y este estilo lo diferencia de otros carnavales como argumenta Morera:

Aquí, más que exhibirse [visualmente], lo que se busca es representar con fidelidad al personaje o a la idea que se quiere [transmitir]. Entonces, eso es lo que creo que lo diferencia del resto. Y hay una cosa en el Carnaval de Cádiz que cada vez estamos usando menos: la imaginación, el convertir que un colador sea una hombrera, que un cepillo sea los galones de no sé quién, que hagan unas medallas con Sugus... (Manuel Morera, 2018, declaraciones en el programa de radio Mira que te diga).

«El pensamiento reflexivo sobre el chiste destruye el humor» (Checa y Olmos, 1992, p. 57), mencionamos esto ya que un cuplé o pasodoble no se explica por la agrupación, o casi nunca, a no ser que vayan enlazados. En televisión o en la radio son los locutores los que se encargan de explicarlo entre copla y copla si fuera necesario (Fernández Jiménez, 2020b). Si en cada chiste tuviéramos que detenernos a describir y detallar la situación, ya no sería un chiste ya que estos se caracterizan, entre otras cosas, por su brevedad. 
Estrella Fernández-Jiménez "La glocalización del Carnaval de Cádiz en sus agrupaciones através de la comunicación no verbal. Lo que dicen sin hablar ni cantar". Comunicación y Hombre. 2022, $n^{\circ} 18$, pp 46 - 61. DOI: https://doi.org/ 10.32466/eufv-cyh.2022.18.699.46-61

Si observamos a las agrupaciones que se presentan al COAC (Concurso Oficial de Agrupaciones Carnavalescas) e incluso a las callejeras podemos proponer una catalogación de clases de tipos en función de lo que representan:

a) Tipos que representan alegorías. Estos tipos son sobre todo vistos en comparsas y coros.

b) Tipos que representan a personas, ya sean reales (con nombre y apellidos) o estereotipos sociales. En estos tipos vemos con mayor claridad la representación de la sociedad en el Carnaval de Cádiz.

c) Tipos que representan a animales o cosas humanizadas, a través de la prosopopeya. Estos tipos al igual que los alegóricos no están exentos de crítica social en sus repertorios y también la contienen.

Figura 1. Chirigota «Ricas y maduras» (2011, «El Canijo de Carmona»)

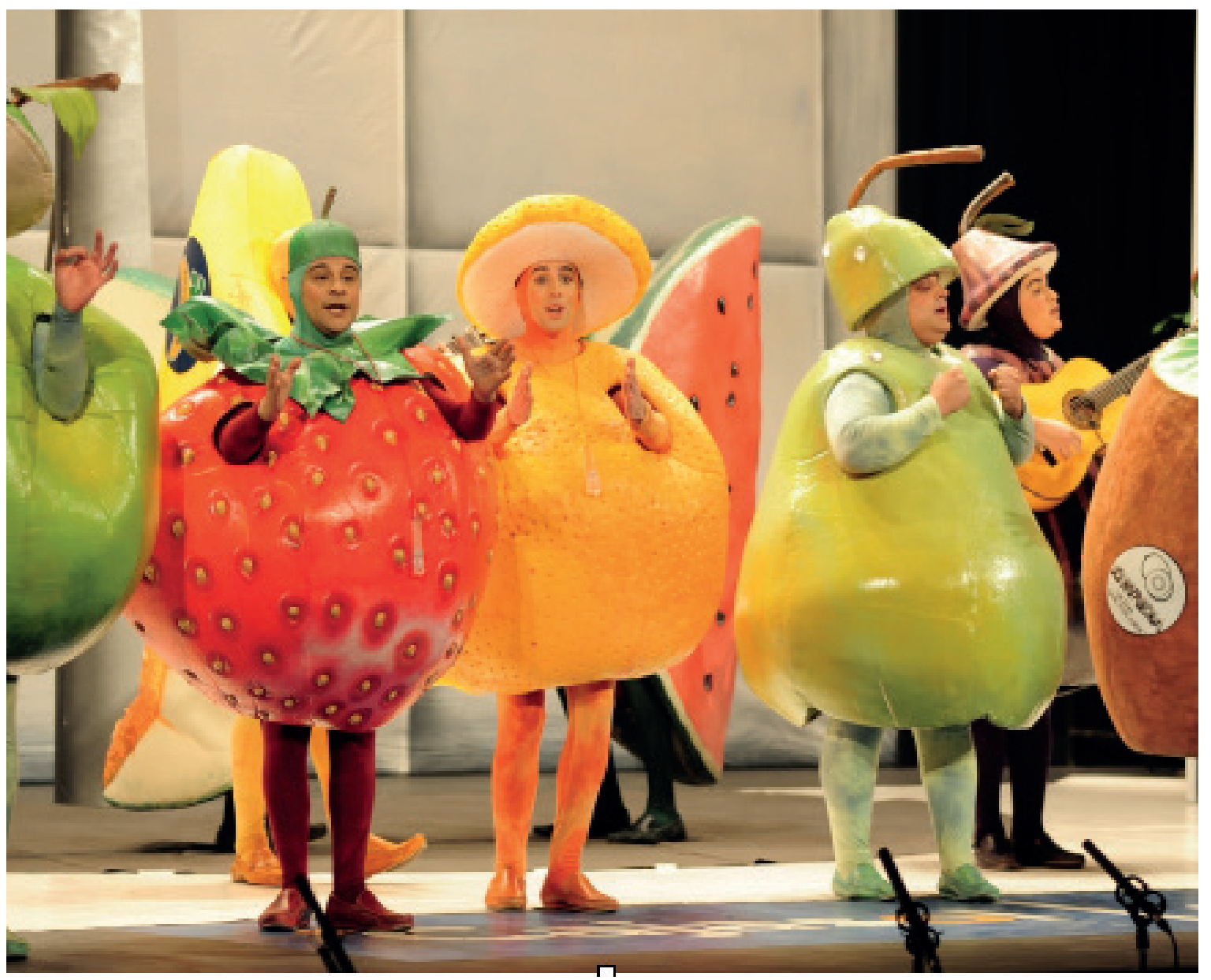

Fuente: Fernando Casas

${ }^{4}$ Atribución, a las cosas inanimadas o abstractas, de acciones y cualidades propias de los seres animados, o a los seres irraciohales de las del ser humano. 
Estrella Fernández-Jiménez "La glocalización del Carnaval de Cádiz en sus agrupaciones através de la comunicación no verbal. Lo que dicen sin hablar ni cantar". Comunicación y Hombre. 2022, $n^{\circ} 18$, pp 46 - 61. DOI: https://doi.org/ 10.32466/eufv-cyh.2022.18.699.46-61

Por otra parte, las agrupaciones también se pueden clasificar según el tipo que utilizan $^{5}$ :

1) El tipo único. Todos los componentes de la agrupación representan a un solo personaje. [Comparsa «El Creador» y «Los Peregrinos» o chirigota «Los Enteraos»].

2) La agrupación liderada. Un componente es diferente a los demás y en general tiene un rol de autoridad. [Chirigota «Una Chirigota con Clase», «La Maldición de la lapa negra» 0 «Los Aleluya»].

3) Agrupación en la que cada componente tiene un rol diferente. (Chirigota «Las muchachas del Congelao», comparsa «Los Carnívales») y en general todos los cuartetos. «El disfraz carnavalesco no tiene una finalidad práctica, sino artística» (Cuesta Torre, 2010, p. 46). Entendemos que en el caso del Carnaval de Cádiz el disfraz como tipo sirve para caracterizar a la agrupación y al repertorio y consecuentemente todos son prácticos. Y después, en mayor o menor medida son artísticos. Muchos tipos de carnaval se basan en imitaciones de personas reales que son parodiadas. En muchos de estos tipos se ve la influencia de la globalización, ya que muchos ya no son tan locales y se basan en personajes globales, como pueden ser series de televisión o películas (Fernández Jiménez, 2020a).

La caricatura puede ser injusta, errónea, facilona o incluso de mala calidad, pero en el peor de los casos induce a reconsiderar lo caricaturizado, a observarlo siquiera durante unos instantes bajo esa nueva luz humorística y a comparar el original con su reconstrucción cómica para valorar la fidelidad del retrato (Romero Reche, 2008, p. 160).

El éxito de las agrupaciones carnavalescas dependerá, aparte de por sus letras, por el tipo que lleven ese año. Si el tipo «está conseguido» la agrupación formará automáticamente parte del imaginario colectivo y el público no tendrá que hacer muchos esfuerzos mentales para comprenderlos puesto que el estereotipo ayuda a adelantar acontecimientos, a realizar previsiones.

Por otra parte, el gran desembolso económico que hacen las agrupaciones para cuidar los tipos es un reflejo de la importancia que otorgan al cuidado de la apariencia en el concurso.

Figura 2. Tweet de Manuel Morera publicado el 4 de enero de 2018.

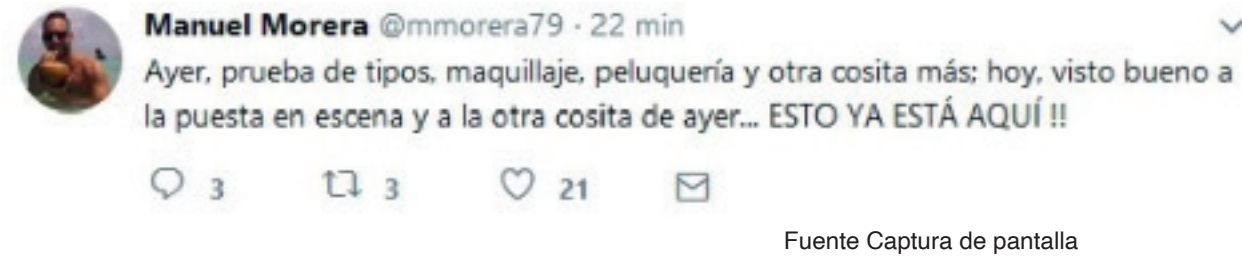

Este tweet de Manuel Morera (cuartetero) muestra que el día 4 de enero la agrupación ya lo tenía todo preparado para el concurso de ese año en el cual resultaron ganadores con «El Equipo A minúscula. Comando Caleti». 
Estrella Fernández-Jiménez "La glocalización del Carnaval de Cádiz en sus agrupaciones através de la comunicación no verbal. Lo que dicen sin hablar ni cantar". Comunicación y Hombre. 2022, $n^{\circ} 18$, pp 46 - 61. DOI: https://doi.org/ 10.32466/eufv-cyh.2022.18.699.46-61

Dicho cuarteto parodiaba la famosa serie de televisión «El Equipo A» e iban caracterizados como los cuatro integrantes del Equipo (y un miembro más), luego que se parecieran era importante. Este cuarteto es un ejemplo claro de glocalización del Carnaval de Cádiz. En apariencia, como decimos, remitían a la serie de televisión «El Equipo A», ahí su componente global, pero el contenido era completamente local «Comando Caleti». Lo no verbal daba pie al contenido del cuarteto.

\section{3. ¿Qué es la comunicación no verbal?}

Todo lo que no es palabra, todo lo que nos rodea es comunicación no verbal: «La comunicación no verbal es el envío y/o recepción de información e influencia a través del entorno físico, la apariencia física y la conducta no verbal» (Patterson, 2011, p. 19). Es decir, nuestra ropa, nuestro peinado, nuestros zapatos, la manera en la que está decorado nuestro despacho o nuestra casa. Con todo esto estamos dando y recibiendo información aunque sea de manera inconsciente. Retomamos la idea de la sal y la pimienta de Solís (1966). No percibimos, no somos conscientes, de esos componentes en los platos, pero como no esté en adecuada proporción puede estropear el resultado por exceso o por defecto. Lo mismo ocurre con lo no verbal.

En las agrupaciones carnavalescas los campos de experiencia (Rodrigo Alsina, 2007) son muy importantes para la adecuada comprensión del mensaje. Cuando hablamos de comunicación no verbal tampoco estamos aludiendo exclusivamente a aspectos físicos, también hablamos de los decorados, del atrezo y el forillo de las agrupaciones carnavalescas, por ejemplo.

Las señas vocales se refieren a diversos aspectos del habla como son el volumen, el tono, la frecuencia, la entonación y las pausas. Aunque estas señales pueden afectar al significado de lo que estamos diciendo, son diferentes de los aspectos verbales de la comunicación (Patterson, 2011, p. 19).

Es decir, que volumen, tono, frecuencia o velocidad, entonación y pausas forman parte de la comunicación no verbal.

Los autores y los directores de las agrupaciones usan estos matices de manera consciente o inconsciente -sobre todo chirigotas y cuartetos- para que su puesta en escena y transmisión de sus coplas se hagan de la mejor manera posible.

\section{1. Características de la comunicación no verbal}

\section{1. 1. Incesante (siempre activa)}

- $\quad$ El canal no verbal está siempre activo mediante los canales visual, auditivo, táctil u olfativo 
Estrella Fernández-Jiménez "La glocalización del Carnaval de Cádiz en sus agrupaciones através de la comunicación no verbal. Lo que dicen sin hablar ni cantar". Comunicación y Hombre. 2022, $n^{\circ} 18$, pp 46 - 61. DOI: https://doi.org/ 10.32466/eufv-cyh.2022.18.699.46-61 comunicación interpersonal;

El envío y recepción de información se dan de manera simultánea en la

Se produce de manera inconsciente; Es muy eficiente para el poco esfuerzo cognitivo que supone, según Patterson somos «tacaños cognitivos» (Patterson, 2011, pp. 22-25).

Como decíamos anteriormente, no tenemos una idea total del tipo hasta que no lo vemos, ya sea desde el propio teatro o desde la retransmisión del concurso. Al estar siempre activa, también son importantes los momentos en los que la agrupación entre copla y copla no canta, pero sí interpreta.

\section{1. 2. El contexto}

Otra característica de la comunicación no verbal es que está muy circunscrita al contexto en el que se produce la acción comunicativa. Hay diferencia entre escuchar o ver un cuplé dentro del contexto del concurso o de la calle, a verlo o escucharlo de manera aislada, sin el contexto de interpretación.

«Con pocas excepciones, la comunicación no verbal solo tiene sentido en el mismo momento que sucede» (Patterson, 2011, pp. 22-25).

«El significado del mensaje está contenido siempre en el contexto, y jamás en algún movimiento aislado del cuerpo. [...] Nunca lograremos tener un diccionario fiable de gestos inconscientes, porque el significado debe buscarse siempre solamente dentro del contexto general» (Davis, 2000, pp. 47-48).

- $\quad$ «La mayoría de los movimientos del cuerpo carecen de un significado social concreto y exclusivo: adquieren significado al ejecutarse en el marco de una relación y contexto determinado» (Baró Catafau, 2012, p. 44).

Como apunta Patterson (2011, p. 73), siguiendo a Hall en su libro Más allá de la Cultura (1976), existen dos tipos de culturas: las de alto contexto y las de bajo contexto. En las culturas de bajo contexto los mensajes se transmiten de manera clara y directa, se utiliza un lenguaje sin ambigüedades y con significado claro. Por el contrario, en las culturas de alto contexto los mensajes se tienen que «leer entre líneas». El significado no está explícito, sino implícito. En esta cultura la comunicación no verbal es fundamental para no dar lugar a interpretaciones erróneas. Consideramos la cultura andaluza cultura de alto contexto luego, las representaciones sociales del Carnaval de Cádiz entrarían en las culturas de alto contexto. Esto podemos relacionarlo con lo obvio y lo obtuso de Roland Barthes.

\section{1. 3. La información adicional (lo que no te dice la copla)}

«La comunicación no verbal proporciona a hablantes y oyentes información adicional sobre el contenido verbal y la expresión del oyente proporciona una reacción no verbal al mensaje del hablante» (Patterson, 2011, p. 116). En el caso del Carnaval de Cádiz la interacción con el público y la reacción del mismo son fundamentales para entender qué está pasando. «Un gesto puede anular por completo un discurso cargado de argumentos» (Baró Catafau, 2012, p. 23). De esto tratan muchos de los giros humorísticos de las coplas. 
Algunas agrupaciones se arriesgan al basar sus «chistes» o golpes humorísticos en gestos, ya que o bien los que lo escuchan por radio no lo entenderán (ya que no lo ven) o bien la realización televisiva puede no llegar a tiempo o captar el momento. Pero es algo que realmente no es primordial a la hora de crear el repertorio. Además, hay que hacer hincapié que las representaciones de las agrupaciones están muy cerca del género teatral y algunos de estos autores interpretan para las personas que están en el teatro sabiendo que quizá quien está siguiendo el concurso por la radio no entienda lo que pasa, o incluso por televisión al no ser captado el gesto por las cámaras. Asumen esas consecuencias en beneficio de un mayor dinamismo en la interpretación.

En verdad esto está hecho como teatro ¿no? y claro, una obra de teatro es difícil retransmitirla por radio. Entonces, al final, si tienes que decidir haces un espectáculo más para el que te ve más que para el que te oye, aunque está bien que te oigan, pero tú no puedes prescindir de algún gesto que te vaya a resolver alguna situación del repertorio por el que te está escuchando por la radio y prefiero hacerlo. (José Luis García Cossío «El Selu», 2018, declaraciones en el programa de radio Mira que te diga). En el caso de los cuartetos es muy complicado realizar un repertorio solo de contenido verbal (decimos actualmente, ya que los cuartetos clásicos podían basar gran parte del repertorio en el contenido verbal, pudiendo permanecer estáticos en el escenario). Por radio se encargan los locutores de explicar qué ha sucedido y por televisión todo está pensado para que no se pierda el chiste, y si se pierde los presentadores que sí se encuentran en el teatro irían al rescate de los telespectadores que no lo han visto explicando lo sucedido (Fernández Jiménez, 2020b). En las agrupaciones callejeras las limitaciones de lo no verbal están en las barreras físicas propias de la calle: aglomeraciones, estatura de componentes y espectadores, etc.

\section{Creación de las representaciones sociales a través de la comuni- cación no verbal y su análisis}

Se le atribuye a la televisión el alto nivel de detalle del decorado y la sofisticación de los maquillajes de las agrupaciones. Esto es admitido siempre y cuando el contenido de las letras no quede en un segundo plano, como anteriormente hemos destacado:

No tiene nada que ver que si tú quieres que la imagen visual de tu agrupación: comparsa, chirigota, coro... sea más acorde a la televisión, no tiene porqué abandonar el contenido. Lo que se critica es que la gente abandone el contenido por eso (Antonio Serrano «El Canijo de Carmona», 2015, entrevista en Fernández Jiménez, 2016).

En Cádiz, los disfraces o tipos de, por ejemplo, las chirigotas no son tan ostentosos como en otros carnavales (aunque sí pueden llegar a serlo). Y no lo son porque se considera que la ostentación no es necesaria para representar estereotipos de la vida cotidiana, base de este carnaval.

Al vestir [al tipo de «Los Enteraos»] tenía que tener una explicación: le puse una chaqueta un poco así apretadilla, el tío tiene que ser un señor, pero estaba tieso, así que su tocado, su gorro era muy barato, era de paja, la chaqueta le estaba estrecha, con muchos años y todo eso le daba el sentido de la impostura que tenía el personaje [...] «Los lacios» era [un tipo] muy apretado. Los pantalones eran muy apretados, la rebeca era muy apretada, para que diera la impresión de un personaje agobiado, 
Estrella Fernández-Jiménez "La glocalización del Carnaval de Cádiz en sus agrupaciones através de la comunicación no verbal. Lo que dicen sin hablar ni cantar". Comunicación y Hombre. 2022, $n^{\circ} 18$, pp 46 - 61. DOI: https://doi.org/ 10.32466/eufv-cyh.2022.18.699.46-61

que con el lenguaje no verbal se viera que era un personaje que estaba incómodo, en «la incomodidad que vivía». El hecho de llevar esa ropa hacía que la gente lo viera incómodo, inquieto y conseguíamos ese resultado. (José Luis García Cossío «El Selu», 2018, declaraciones en el programa de radio Mira que te diga).

Figura 3. Chirigota «Los Enteraos» (2009 «El Selu»).

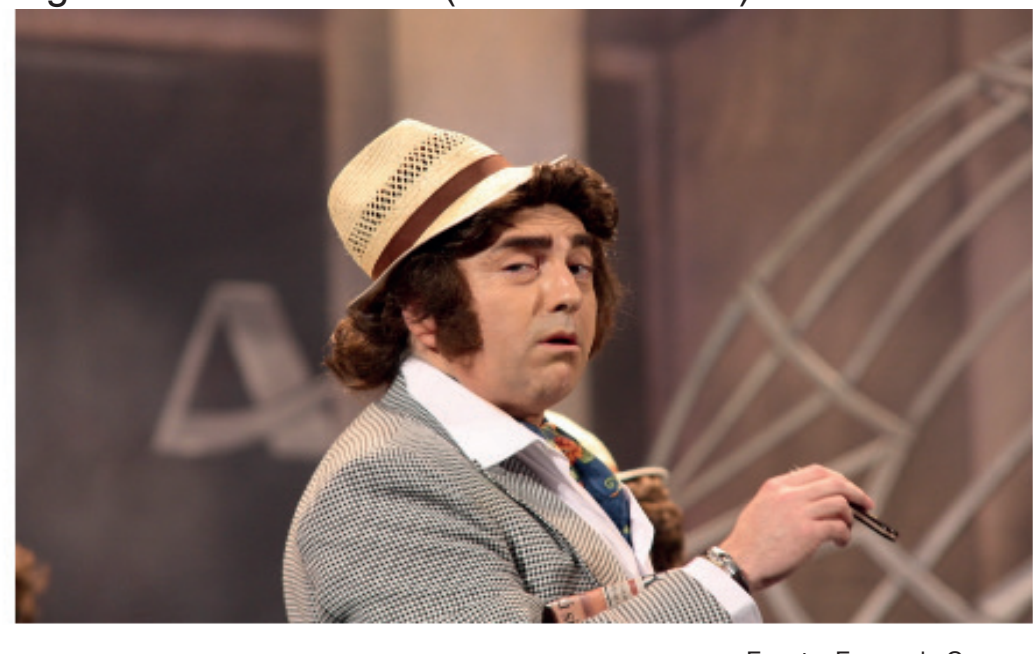

Fuente: Fernando Casas

De la descripción de «El Selu» se desprende que podemos deducir la psicología del personaje y lo que podemos esperar de él observando cómo va vestido. Hemos concretado aquí el caso de la chirigota puesto que en otras agrupaciones como el coro y, sobre todo la comparsa, los tipos sí son muy vistosos (Ejemplo de «El perro andalú», Martínez Ares, 2018). En las chirigotas los tipos suelen ser tachados de groseros y grotescos, no faltos de razón como por ejemplo «Los pichas de Cádiz» («El Love», 2006). «La exageración (hiperbolización) es efectivamente uno de los signos característicos de lo grotesco [...] pero no es, sin embargo, el signo más importante» (Bajtin, 1990, p. 276). Por otro lado, «la mezcla de rasgos humanos y animales es una de las formas grotescas más antiguas» (Bajtin, 1990, p. 284) es decir, que nos encontraríamos con casos de «teriomorfismo» (Durand, 2006, p. 73) o la prosopopeya que mostramos anteriormente.

Parece que en la fiesta se alterna la utilización del lenguaje oral con los lenguajes de carácter no verbal (kinesia, gestos, posturas, ritmos corporales, comunicación por el tacto, por el rostro, por el uso del espacio, etc.), lo cual denotaría el origen antiguo y primitivo de la Fiesta y su carácter de gozne entre lo humano y lo prehumano, casi animal. Es de destacar, asimismo, el escasísimo o nulo uso de lenguajes escritos, solo con carácter de apoyo a los otros tipos y, generalmente, de forma «redundante», para aclarar determinados significados (Roiz Célix, 1982, pp. 122-123).

Históricamente las canciones de los trovadores y las historias que pasan de padres a hijos han perdurado gracias a la transmisión de boca en boca, pero además, esta transmisión también se producía «de gesto en gesto». «[las palabras] son solo el comienzo, porque detrás de ellas está el cimiento sobre el cual se construyen las relaciones humanas: la comunicación no verbal» (Davis, 2000, p. 21).

Coloquialmente que no tiene dinero. 
Estrella Fernández-Jiménez “La glocalización del Carnaval de Cádiz en sus agrupaciones através de la comunicación no verbal. Lo que dicen sin hablar ni cantar". Comunicación y Hombre. 2022, $n^{\circ} 18$, pp 46 - 61. DOI: https://doi.org/ 10.32466/eufv-cyh.2022.18.699.46-61

Y a veces la clave en alguna letra de carnaval o relato está en los gestos.

La comunicación no verbal está compuesta por el atrezo, el forillo, el propio tipo de las agrupaciones, etc. y los autores tienen que crear también los gestos, los movimientos, la pose, el talante e incluso el timbre y el volumen de la voz, aspectos que no pueden reflejarse solo mediante la letra. "La parte visible de un mensaje es por lo menos tan importante como la audible» (Davis, 2000, p. 16). Aunque debemos tener presente que la letra junto a la música (copla) siempre es y será lo más importante en el Carnaval de Cádiz. De hecho, las letras es lo más criticado precisamente por no calibrar lo glocal, es decir, a veces se critican agrupaciones que le cantan más a lo global y menos a lo local.

\section{1. Análisis de la comunicación no verbal en las agrupaciones carnavalescas gaditanas}

Hay que tener presente multitud de elementos no solo cuantitativos sino también cualitativos para un completo estudio de esta comunicación (Forner, 1987, p. 51).

En nuestro caso, nos aprendemos el repertorio y una vez aprendido, nos ponemos de pie y empezamos a interpretar al personaje y por último hacer ya el 4D: un pequeño gesto en la cara, o pequeños ademanes, detalles, o tics, que le dan mucha calidad a lo que se dice. (José Luis García Cossío «El Selu», 2018, declaraciones en el programa de radio Mira que te diga).

La agrupación carnavalesca no termina de estar elaborada cuando el repertorio está escrito. Tras el proceso de escritura, incluso durante el mismo proceso, el autor o director de la agrupación planea la expresión no verbal de todos sus integrantes. El proceso de creación y producción de una agrupación, incluidos los ensayos, suele durar en torno a cinco meses (Fernández Jiménez, 2020c). Para analizar los componentes y los patrones de esta comunicación no verbal seguiremos el esquema de Patterson (2011, pp. 40-54):

- A) Características fijas. Son las características que no van a cambiar en todas las actuaciones que vaya a tener la agrupación.

- A. 1) El diseño y la disposición del espacio: el atrezo, el forillo, los elementos que estarán distribuidos por el escenario en el caso de las agrupaciones concursantes o los elementos que usarán las callejeras. La colocación de los músicos también se tiene en consideración cuando se distribuye el espacio. Generalmente se sitúan detrás de los vocalistas en las comparsas y en las chirigotas. También puede ocurrir que vayan en otro lugar como, por ejemplo, en la chirigota «No te vayas todavía» («El Bizcocho», 2017).

${ }^{8}$ Se recomienda consultar los esquemas explicativos de las posiciones de los componentes de las agrupaciones en el libro de María Luisa Páramo, (2017, pp. 476-477).

${ }^{9}$ Esta chirigota causó gran impacto al aparecer por primera vez en el teatro. La imagen, lo no verbal, hacía que se entendier rápidamente cuál era la situación. Es además una imagen global, ya que en muchas culturas los velatorios son parecidos. 
Estrella Fernández-Jiménez "La glocalización del Carnaval de Cádiz en sus agrupaciones através de la comunicación no verbal. Lo que dicen sin hablar ni cantar". Comunicación y Hombre. 2022, n 18, pp 46 - 61. DOI: https://doi.org/ 10.32466/eufv-cyh.2022.18.699.46-61

Figura 4. Chirigota «No te vayas todavía» (2017, «El Bizcocho»)

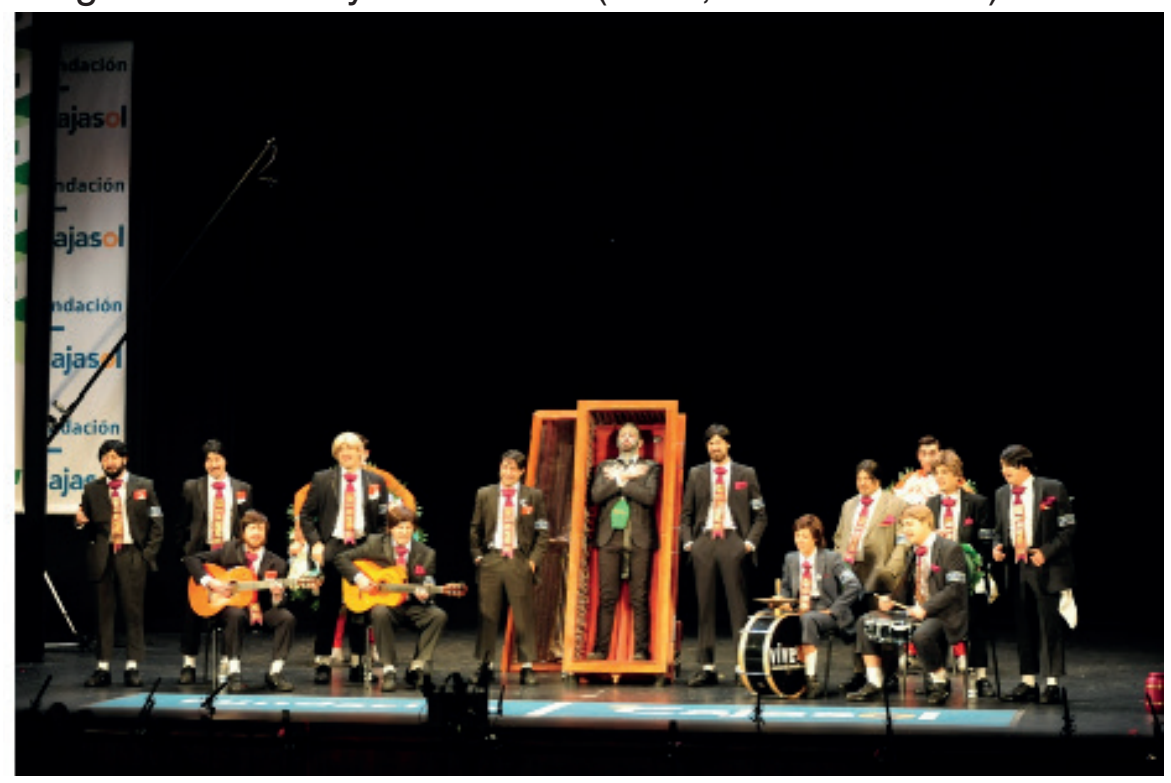

Fuente: Fernando Casas

- A. 2) La apariencia física. En el caso de las agrupaciones, el tipo: ropa y materiales con los que la agrupación conformará al personaje que vayan representando, desde los zapatos hasta el más pequeño detalle que puedan llevar en la cabeza y todos sus complementos. Si bien son «cosas que se mantienen relativamente sin cambio durante el periodo de interacción» (Knapp 1995, p. 24), a veces, por exigencias del repertorio, hay algún cambio de apariencia. Los autores saben que la apariencia comunica, un ejemplo de ello es la comparsa «La Chusma Selecta» (Martínez Ares, 2020) en la que los componentes iban con los diferentes colores de los diversos partidos políticos desde el componente ubicado más a la izquierda, de color morado, al componente ubicado a la derecha, de color verde. Este es un ejemplo de glocalización. Esta comparsa parte de la idea de una agrupación gaditana y con repertorio circunscrito en cierta medida a lo local, pero el hecho de llevar los colores de los partidos políticos que también rigen a nivel nacional, hacen que lo no verbal también sea más general.

Además de la apariencia física alcanzada gracias al atuendo o maquillaje, el autor o director también cuenta con la apariencia física natural de cada intérprete o participante de la agrupación, como indica Morera:

Puede haber personas que pueden ser muy graciosas pero sus gestos, sus lenguaje no verbal te tira para atrás (nosotros usamos mucho esa expresión, tira para atrás o no tira para atrás) y creo que hay grupos que resultan muy agradables y grupos que tiran para atrás sin tener una clave de decir «es por esto» [...]. Es cuestión de eso, de lenguaje no verbal, de expresión, de la cara, de cómo se mueve, de cómo habla, el tono de voz también influye muchísimo cómo digas las cosas. Yo siempre digo que en Cádiz, más de qué dices es el cómo lo dices. Ahí influyen muchísimos factores. (Manuel Morera, 2018, declaraciones en el programa de radio Mira que te diga). 
Estrella Fernández-Jiménez "La glocalización del Carnaval de Cádiz en sus agrupaciones através de la comunicación no verbal. Lo que dicen sin hablar ni cantar". Comunicación y Hombre. 2022, $n^{\circ} 18$, pp 46- 61. DOl: https://doi.org/ 10.32466/eufv-cyh.2022.18.699.46-61

Hasta en repartir los roles también tienes que tener cuidado de hacerlo bien. Tú no puedes poner al más largo de fresa y al más bajito de plátano porque te sale una fresa amorfa y un plátano enano. («El Canijo de Carmona» 2018, declaraciones en el programa de radio Mira que te diga)

- B) Las conductas dinámicas. Una vez se ha anclado al personaje mediante las conductas fijas, las conductas dinámicas son fundamentales para la exposición del repertorio. Estas son más numerosas y con más matices que las fijas.

- B. 1) La distancia y orientación. La orientación en las agrupaciones del carnaval siempre es de cara al público, al igual que una obra de teatro. Ya sea en la calle o en el Teatro han de proyectar la voz de la mejor manera posible hacia el público. La distancia varía si se trata de la calle o del Teatro Falla.

- B. 2) La conducta visual. Generalmente, todos los componentes de las agrupaciones, ya sea en coros, comparsas, chirigotas, cuartetos y romanceros, miran al frente, hacia el público quien es el destinatario de sus coplas y gestos. Antonio Serrano «El Canijo de Carmona» hace referencia a la importancia de tener los ojos grandes para expresar bien y conectar. (Antonio Serrano «El Canijo de Carmona», 2018 declaraciones en el programa de radio Mira que te diga).

Por ejemplo, en la chirigota «Los Enteraos» («El Selu», 2009), las miradas del personaje son fundamentales para la transmisión del mensaje (Véase Figura 3).

- B. 3) La expresión facial. «De todas las zonas del cuerpo, el rostro es la que parece provocar la mejor retroalimentación externa e interna, lo que facilita la adaptación a una gran variedad de reglas de expresiones faciales» (Knapp, 1995, p. 252). Uno de los aspectos distintivos del Carnaval de Cádiz frente a otros carnavales es que el de Cádiz no usa máscaras ni caretas. Puesto que en la mayoría de ocasiones van representando estereotipos sociales, personas, y solo hacen uso del maquillaje. El uso de las máscaras no permitiría proyectar la voz al cantar.

- B. 4) La postura y el movimiento.

Las posturas, como estáticas (pues lo que puede hacerlas «moverse» será una manera o modo) e igualmente conscientes o inconscientes, también ritualizadas y, como en el caso de las maneras, menos utilizadas como formas de un repertorio comunicativo, aunque, a semejanza de gestos y maneras, comunican de todas formas el sexo, la posición social, el origen cultural, el estado de ánimo, etc. (Poyatos 1994: 201). [Cursivas del autor].

Estos dos componentes, como los anteriores, dependerán del tipo que vaya representando cada agrupación y también de la modalidad a la que pertenezca.

- B. 5) Los gestos. «Los gestos son movimientos de las manos, brazos e incluso de la cabeza que están estrechamente relacionados con el contenido verbal del mensaje» (Patterson, 2011, p. 49). El Carnaval de Cádiz es el carnaval de las coplas (Páramo, 2017), pero la quinésica además de la gestualidad tiene un gran peso en las agrupaciones más allá del cuarteto, como en este trabajo mostramos. Las agrupaciones no necesitan moverse mucho para transmitir sus letras, pero creemos que el movimiento es fundamental y no ha de estar relegado en importancia ya que además del texto entran en juego todos los elementos que aquí estamos mencionando, elevándose así su potencial de transmisión de las coplas.

- B. 6) El contacto corporal. Como en cualquier otra representación teatral, el contacto corporal entre los intérpretes dependerá del tipo, persona o personaje que vayan repre- 
Estrella Fernández-Jiménez "La glocalización del Carnaval de Cádiz en sus agrupaciones através de la comunicación no verbal. Lo que dicen sin hablar ni cantar". Comunicación y Hombre. 2022, $n^{\circ} 18$, pp 46- 61. DOI: https://doi.org/ 10.32466/eufv-cyh.2022.18.699.46-61

sentando. Los integrantes pueden empujarse, pegarse, abrazarse e incluso besarse si

la letra y el personaje lo requiere.

- B. 7) Las conductas vocales. «Las conductas vocales se refieren no a lo que se dice, sino a "cómo" se dice. Aquí se incluye el tono, la intensidad, el énfasis y el tempo del discurso. (...) el acento de los hablantes suele indicarnos sus lugares de origen» (Patterson 2011, p. 52). Es decir, el paralenguaje nos informa de elementos que van más allá de las palabras, o en nuestro caso, de la letra de las coplas. Como señala Manuel Morera:

Se da la situación y luego ves que a esa situación le cabe un gesto, una expresión o una coletilla. [...] por ejemplo «Don Antonio» no estaba escrito «Don Antonio» en el papel, o a lo mejor estaba escrito «Don Antonio», no me acuerdo. Pero la forma de interpretarlo es de Carlos, o sea, ese «Don Antonio» es de él de cada ensayo y si nos gusta se queda. (Manuel Morera, 2018, declaraciones en el programa de radio Mira que te diga).

«Las variaciones [de expresión vocal y mímica de un actor] son dictadas por las situaciones dramáticas y por las exigencias de la puesta en escena» (Kowzan 1997, p. 61). Otro elemento a considerar dentro de la comunicación no verbal es el acento que adoptan las agrupaciones: en muchas ocasiones, las agrupaciones de carnaval adoptan el acento del grupo social al que van representando, incorporando así aspectos no verbales a la verbalización del contenido. Hace referencia al cómo se dice, no al qué se dice, luego forma parte de la comunicación no verbal.

- B. 8) Las señales olfativas. Uno de los canales que siempre está activo es el canal olfativo, y las agrupaciones carnavalescas también lo tienen presente. Ya en 1964 Paco Alba ambientó su actuación de «Currusquillos gaditanos» con olor a canela; en la chirigota «Ricas y Maduras» («El Canijo de Carmona», 2011) los componentes se echaban colonia afrutada antes de salir; la chirigota «iViva la Pepi!» («El Selu», 2012), en sus actuaciones usaban ambientadores, o el Coro «La Boutique» (Francisco Martínez Mora, 2014) olía a chocolate.

Todos estos componentes unidos, o también por separado, hacen que los componentes de las agrupaciones se transformen en actores y se produzca un pacto de ficción sin esfuerzos por parte del espectador.

Como decíamos, los autores y directores de carnaval, tal vez de manera inconsciente, tienen en consideración en todo momento todos estos elementos de la comunicación no verbal y se sirven de ellos para conseguir que su agrupación transmita las ideas que quieren expresar.

\section{Conclusión}

La comunicación no verbal es una herramienta fundamental para la representación de la sociedad en el Carnaval de Cádiz.

${ }^{10}$ «El sarcasmo es otro ejemplo que demuestra la importancia de la conducta vocal. En este caso, cambiando la forma en que hacemos una afirmación, el significado del enunciado sarcástico es justamente el opuesto del que nos indica el contenido verbal» (Patterson, 2011, pp. 40-54). Fundamental en chirigotas y cuartetos. 
Imperando el contenido de las coplas (letra y música), no hay que desdeñar la importancia que tienen el atrezo, el forillo, los utensilios, y sobre todo el tipo, los gestos, los movimientos, el timbre y el tono con el que se dicen las cosas. Estos elementos destacados ayudan a los autores y componentes a mostrar de la mejor manera posible el tipo o el personaje que van representando.

Hemos visto que la glocalización que consiguen las agrupaciones del carnaval gaditano en cierta medida es conseguida gracias a su comunicación no verbal. Puede ocurrir que sin escuchar la letra, componente fundamental de las agrupaciones, un grupo consiga llamar la atención o, por el contrario, lograr el resultado inverso, que cause rechazo por exceso o por defecto.

La sal y la pimienta, como apuntaba Solís (1966), sabemos que es el aderezo de los platos principales y el aderezo de la comunicación verbal. Pero tras este estudio en lugar del aderezo quizá lo no verbal lo podríamos tratar de guarnición que acompaña al plato principal. Sería demasiado arriesgado afirmar que la comunicación no verbal es lo principal, incluso una exageración ya que como señala Páramo $(2017$, p. 115) «Se trata de un concurso de coplas, no de artes escénicas, aunque estas ayuden a dotar de un envoltorio más atractivo y eficaz a las coplas de carnaval». Aun así, lo no verbal tiene una gran importancia en las agrupaciones gaditanas y en ocasiones no solo forma parte del envoltorio y va más allá como aquí hemos mostrado.

Como conclusión secundaria vemos que el Carnaval de Cádiz además de ser una fuente inagotable de estudios antropológicos, artísticos, históricos y sociales, lo es también para los estudios de Comunicación audiovisual, ya que constantemente activa los sentidos del oído (audio) y de la vista (visual) y en este último lo no verbal es crucial.

\section{Bibliografía}

Amossy, R. y Herschberg, A (2001). Estereotipos y clichés. Buenos Aires: Eudeba. Barceló Calatayud, A. (2016). El tipo en el Carnaval de Cádiz. Propuesta para una catalogación. Cádiz: Quorum.

Baró Catafau, T. (2012). La gran guía del lenguaje no verbal. Cómo aplicarlo en nues tras relaciones para lograr el éxito y la felicidad. Barcelona: Paidós.

Bajtin, M. (1990). La cultura popular en la Edad Media y en el Renacimiento. El con texto de François Rebelais. Madrid: Alianza.

Barthes, R. (1986). Lo obvio y lo obtuso. Imágenes, gestos, voces. [Versión digital]

Barcelona: Paidós, pp. 69-92 y 243-278.

Checa y Olmos, F. (1992). El humor andaluz, ¿Identidad de un pueblo?. En El Folklo re Andaluz. Revista de cultura tradicional, 8, Fundación Machado, pp. 55-84.

Cuesta Torre, M. L. (2010). Banquete, batalla y disfraz: Elementos carnavalescos en los inicios del teatro castellano. José María Balcells (Ed.). El Carnaval: Tradición y actualidad. León: Universidad de León, pp. 43-53 y 60-61.

Davis, F. (2000). La comunicación no verbal. Madrid: Alianza.

Durand, G. (2006). Las estructuras antropológicas del imaginario. Introducción a la arquetipología general. México: Fondo de Cultura Económica.

Fernández Jiménez, E. (2015). Acercamiento a la creación de chirigotas gaditanas. En Creatividad y Sociedad, número 24, páginas 64-88. 
Estrella Fernández-Jiménez "La glocalización del Carnaval de Cádiz en sus agrupaciones através de la comunicación no verbal. Lo que dicen sin hablar ni cantar". Comunicación y Hombre. 2022, $n^{\circ} 18$, pp 46- 61. DOI: https://doi.org/ 10.32466/eufv-cyh.2022.18.699.46-61

Fernández Jiménez, E. (2016). El potencial comunicativo de las chirigotas gaditanas y su realización televisiva. Sevilla [Tesis doctoral inédita].

Fernández Jiménez, E. (2018). La Final del Falla: Un estudio sobre la realización tele visiva del COAC. Cádiz: Servicio de Publicaciones de la Universidad de Cádiz.

Fernández Jiménez, E. (2020a). Representación audiovisual de personajes de ficción en el carnaval de Cádiz. Hipercultura popular. En Revista Comunicación, Vol. 1, $\mathrm{N}^{\circ}$ 18, pp. 119-135. https://dx.doi.org/10.12795/Comunicacion.2020.i18.07

Fernández Jiménez, E. (2020b). Características periodísticas en la retransmisión de cultura popular: Concurso Oficial de Agrupaciones Carnavalescas de Cádiz. En (Nuria Sánchez-Gey Valenzuela \& Susana Alés Álvarez) Los Medios de Comunica ción como agentes de educación social. Sevilla: Ediciones Egregius.

Fernández Jiménez, E. (2020c). El proceso creativo de las agrupaciones carnava lescas de Cádiz. En Vivat-Academia. Revista de Comunicación. № 153. pp. 29-53. https://doi.org/10.15178/va.2020.153.29-53

Forner, Á. (1987). La Comunicación no verbal. Actividades para la escuela. Barcelona: Grao de Serveis Pedagogics.

Knapp, M. L. (1995). La comunicación no verbal. El cuerpo y el entorno, Barcelona: Paidós, $5^{\circ}$ ed.

Kowzan, T. (1997). El signo y el teatro. Madrid: Arco Libros.

Páramo Fenández-Llamazares, M. L. (2017). El carnaval de las coplas, un arte de Cádiz. Madrid: Izana editores.

Patterson, M. L. (2011). Más que palabras: el poder de la comunicación no verbal.

Barcelona: Universidad Oberta de Cataluña.

Poyatos, F. (1994) La comunicación no verbal II. Paralenguaje, kinésica e interacción, Madrid: Istmo.

Ramos Santana, Alberto (2002). El Carnaval Secuestrado o Historia del Carnaval. El caso de Cádiz. Cádiz, Quorum Editores.

Rodrigo Alsina, M. (2007). Los Modelos de la Comunicación. Madrid: Tecnos.

Roiz Célix, M. (1982). «Fiesta, comunicación y significado». En Honorio Velasco. Tiempo de Fiesta. Ensayos antropológicos sobre las fiestas en España. Madrid: Tres-Catorce-Diecisiete, pp. 95-124.

Romero Reche, A. (2008). El humor en la teoría sociológica postmoderna. Una pers pectiva desde la sociología del conocimiento. [Tesis doctoral] Granada: Editorial de la Universidad de Granada.

Sacaluga I. y Pérez, Á. (2017). (Coord.) El Carnaval de Cádiz. De las coplas a la in dustria cultural. Cádiz: Editorial UCA.

Solís Llorente, R. (1966). Coros y Chirigotas. (Las letras del Carnaval gaditano). Ma drid: Tauro Ediciones.

Mira que te diga. Programa radiofónico de IndessMedia (Universidad de Cádiz).

Producción: Estrella Fernández Jiménez. [Parte 1: https://www.youtube.com/watch?v=NBsgJmGRso8 Parte 2: https://www.youtube.com/watch?v=ocLi_sAWd0o] (Consultado el 3 de abril de 2018). 